\title{
Eimeria sp. Infection in Black Bucks (Antilope cervicapra) of Tal Chhapar Sanctuary of Rajasthan
}

\author{
A. K. Chouhan, P. K. Pilania, Monika*, D.B. Sodha, Bhavana Rathore, \\ D.P. Pateer and Anand Kumar
}

Department of Veterinary Parasitology, College of Veterinary and Animal Science, Bikaner Rajasthan University of Veterinary and Animal Sciences, Bikaner-334001, India

*Corresponding author

\section{A B S T R A C T}

Keywords

Antilope

cervicapra, Eimeria

sp., Prevalence,

Rajasthan, Tal

Chhapar Sanctuary,

Wildlife

Article Info

Accepted:

12 December 2020

Available Online:

10 January 2021
A total of 632 faecal samples were collected from Tal-Chhapar Sanctuary of Rajasthan during summer, rainy and winter season from November 2018 to September 2019 and examined qualitatively by faecal floatation for Eimeria sp. oocysts and quantitatively by modified McMaster egg counting technique. Coprological analysis of samples revealed an overall prevalence of $22.78 \%$ for Eimeria sp. Quantitative analysis revealed oocyst per gram (OPG) of faeces ranging from 300-2300 with an average of $704.35 \pm$ 107.72.Seasonal study revealed highest infection in rainy season $(34.98 \%)$ followed by winter (19.80\%) and summer season (12.56\%). Statistical analysis using multivariate binary logistic regression model revealed highly significant difference $(\mathrm{P}<0.01)$ in the prevalence of Eimeria sp. infection among different seasons.

\section{Introduction}

The blackbuck (Antilope cervicapra) is the sole living member of the genus Antilope in Indian subcontinent and plays important ecological roles in grassland ecosystem. It has genetic, medicinal, scientific, aesthetic and recreational value (Kunwar, 2015) and also has cultural value in Hinduism and Buddhism (Khanal, 2006). The blackbuck has recently moved from the "Near threatened" to "Least
Concern" in Red Data Book of IUCN (IUCN, 2017) and categorized in Appendix III of CITES. Rajasthan state comprises highest blackbuck population among 13 states of India in which blackbucks are found (FSI, 2015). The blackbuck population is at significant threat due to poaching and destruction of habitats including health related issues (Meena and Saran, 2018). Wild animals suffer from a variety of infectious and non-infectious diseases, particularly that of 
parasitic origin (Akhter and Arshad, 2006; Lama et al., 2015). Blackbucks are susceptible to various kinds of parasitic infections like coccidiosis, paramphistomiasis, fascioliasis, schistosomiasis, taeniasis and nematodiasis (Thornton et al., 1973). Wildlife parasitic diseases represent an important field of investigation as they may have a significant impact on wild animal health, and may also have public health concern (Liatis et al., 2017).

Coccidiosis is an important stress induced enteric protozoan parasitic disease affecting several animal species including wild ruminants and caused by various species of microscopic apicomplex an organism Eimeria. A number of epidemiological factors like moisture, temperature, and oxygen tension influence the disease pattern and stress factors like weaning, change of diet, harsh environment, poor nutrition and overcrowding can increase level of infection and incidence of the disease due to stressinduced immunosuppression (Urquhart, 1996).

Adequate data on parasitic infections of wild animals are not available due to lack of systematic investigations (Varadharajan and Kandasamy, 2000). Only as few studies for coccidia prevalence in black bucks have been carried out in India by Pilania et al., (2014) and Mir et al., (2016) in Rajasthan and Punjab state, respectively. Information on coccidia infections of blackbucks is scanty in Rajasthan. No such study in Tal-Chhapar sanctuary has been reported so far.

Keeping in view the significance of the parasite as an important cause affecting wild ruminants health and paucity of information in the region, the present study has been designed to map the prevalence rate and severity of coccidia infections in black bucks of Tal-Chappar sanctuary along with associated risk factors.

\section{Materials and Methods Study area}

The study area comprises of Tal-Chhapar sanctuary, which is located in Churu district of north-western Rajasthan in Indiaand is spread over 7.19 Sq. Km area. Tal-Chhapar sanctuary comes under principal arid zone of the country and is characterized by large variation in temperature which reaches up to $48^{\circ} \mathrm{C}$ in June and minimum temperature falls below $4^{\circ}$ in December - January. The area is characterized by stormy southwest winds and frequent dust storms with an average rainfall of $300 \mathrm{~mm}$ (D.O.A., Govt. of Rajasthan, www.agriculture.rajasthan.gov.in).

\section{Sampling method and sample size determination}

Simple random sampling technique was conducted to collect the faecal samples from individual study animals for coprological examination. Season was considered as risk factors for the occurrence of coccidia infections in blackbuck population. Since there was no record of previous prevalence in the study area, the sample size was calculated according to Thrusfield (2005) formula by using 50\% expected prevalence with 5\% absolute precision at $95 \%$ confidence interval.

$\mathbf{n}=\underline{\mathbf{z}^{2} * \mathbf{P}_{\exp }} \underline{\mathbf{d}}_{\mathbf{d}^{2}}^{\left(1-\mathbf{P}_{\exp }\right)}$

Where, $\mathrm{n}=$ The sample size

$\mathrm{P}_{\text {exp }}=$ Expected prevalence $(0.5)$

$\mathrm{d}=$ Desired absolute precision (usually $5 \%$ )

$\mathrm{Z}=$ Required confidence level, $(\mathrm{Z}=1.96$ for $95 \%$ confidence interval)

The status of prevalence rate of infection, the expected prevalence of $15 \%$ with confidence limits of $95 \%$ and a desired absolute precision of 5\% was studied by collecting maximum number of representative samples (Thrusfield, 2005). The number of samples thus calculated 
was adjusted for finite population.

\section{Collection of samples}

A total of 632 samples collected randomly from blackbuck population collected from Tal Chhapar Sanctuary of Rajasthan during summer, rainy and winter season from November 2018 to September 2019.

The samples were placed in sterile polythene bags and labelled carefully indicating the host's detail, location and month of collection, kept in a cool transport box and brought to the Laboratory for further examination.

\section{Coprological examination}

Faecal samples were examined by direct smear and standard faecal flotation techniques for detection of coccidian oocysts. The coccidian parasites were identified on basis of the morphological features of oocysts as described by Soulsby (1982). Quantitative faecal examination was done by standard McMaster's technique tocalculate the oocysts per gram (OPG) of faeces (Coles et al., 2006).

\section{Statistical analysis}

All data analyses were performed by using statistical software program (SPSS for Windows, Version 20.0, USA). Association between the prevalence of coccidian infection with various factors (season, district and animal type) was carried out by Chi square $\left(\chi^{2}\right)$ test. Variables with significant association at $\mathrm{P} \leq 0.05$ (two-side) were subjected to the multivariate Binary logistic regression model (Table 2).

The results were each expressed as logistic regression coefficient (B), wald test, Standard error (S.E.), $\mathrm{P}$ value and odd ratio (OR) with a $95 \%$ confidence interval (CI $95 \%$ ).

\section{Results and Discussion}

The overall prevalence of Eimeria sp. Infection in the Blackbucks was recorded $22.78 \%$ during current study. In contrast, higher prevalence have been reported in various wild and captive ruminants including Blackbucks from Punjab (Mir et al., 2016)whereas, a lower prevalence was recorded by Singh et al., (2009) from Bhopal, Madhya Pradesh and Pilania et al., (2014) from Bikaner, Rajasthan. Higher prevalence by Debenham et al., (2016), Chaudhary and Maharjan (2017) and Cao et al., (2019) has been recorded from Tanzania, Nepal and China, respectively. However, the variations regarding prevalence in various studies can most likely be attributed to difference in number and distribution of animals and variation in topography and climatic factors (Das et al., 2018).

Seasonal dynamics of Eimeria sp. infections revealed a highly significant difference $(\mathrm{p}<0.01)$ among seasons with highest prevalence in rainy season $(34.98 \%)$ followed by winter $(19.80 \%)$ and summer season $(12.56 \%)$. No season targeted study for coccidia infection in blackbucks has been reported so far.

Multivariate binary logistic regression analysis for coccidiosis indicated a negative association in summer season and positive association in rainy season as compared to winter season i.e. odd ratio of infection decreased by 0.582 in summer and increased by 2.179 in rainy season with complete details in table 2 . The negative $b$ values of summer (0.542)as compared to winter indicated a decreased prevalence of coccidiosis with increase in ambient temperature (table 2).

Eimeria sp. oocysts with and without micropyle cap has been detected during present study which is consistent to the 
findings of Chaudhary and Maharjan (2017). Due to coccidiosis, the infected hosts generally exhibit loss of appetite, weakness, diarrhoea, particularly in fawns than the adults, resulting in the compromised immune system (Ghimire et al., 2008) indicating its high impact on the survival of blackbucks.

Table.1 Overall and season wise prevalence of Eimeria sp. infection in black bucks of $\mathrm{T}$ al Chhapar Sanctuary, Rajasthan

\begin{tabular}{|l|l|c|c|}
\hline Season & Summer & 207 & $\begin{array}{c}\text { Examined } \\
\text { Infected }\end{array}$ \\
\cline { 2 - 4 } & Rainy & 223 & $\begin{array}{c}78 \\
(12.56 \%)\end{array}$ \\
\cline { 2 - 4 } & Winter & 202 & $\begin{array}{c}74.98 \%) \\
(19.80 \%)\end{array}$ \\
\hline Overall & & 632 & $\begin{array}{c}144 \\
(22.78 \%)\end{array}$ \\
\hline$\chi^{2}$ value & & & $32.165^{* *}$ \\
\hline
\end{tabular}

Note:Figures in parentheses indicate percentage, $*=$ significant, $* *=$ highly significant

Table.2 Multivariate binary logistic regression for Eimeria sp. Infection in black bucks

\begin{tabular}{|l|c|c|c|c|c|c|}
\hline \multicolumn{2}{|c|}{ Parameter } & $\begin{array}{c}\text { Logistic regression coefficient } \\
(B)\end{array}$ & S.E. & $\begin{array}{c}\text { Wald } \\
\text { test }\end{array}$ & $\begin{array}{c}\text { P } \\
\text { value }\end{array}$ & $\begin{array}{c}\text { Odd } \\
\text { ratio }\end{array}$ \\
\hline \multirow{3}{*}{ Season } & Summer & -0.542 & 0.274 & 3.904 & 0.048 & 0.582 \\
\cline { 2 - 8 } & Rainy & .779 & 0.226 & 11.915 & 0.001 & 2.179 \\
\cline { 2 - 8 } & Winter & - & - & 30.424 & 0.00 & - \\
\hline \multirow{2}{*}{ Constant } & & -1.399 & .177 & 62.760 & 0.00 & 0.247 \\
\hline
\end{tabular}

Note: S.E. $=$ Standard Error

Figure.1 Photomicrographs of Eimeria sp. oocysts in blackbucks (a) Oocyst with micropyle (b) Oocyst without micropyle
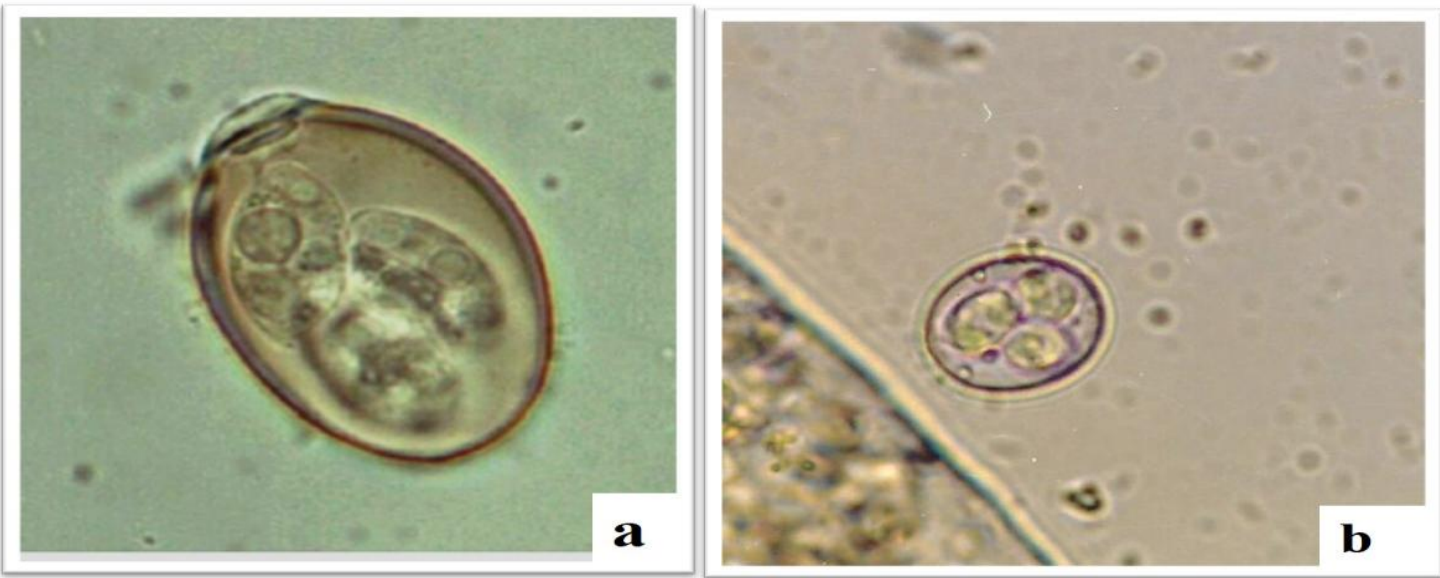
Quantification of the infection by means of oocyst per gram revealed mild to severe infection of Eimeria sp. ranging from 3002300 with an average of704.35 \pm 107.72 which is in close approximation with the findings of Singh et al., (2006).

Contrast to present findings, a lower intensity has been recorded by Mir et al., (2016). The variations may be due to the differences in climate-ecology, management, sample size and time of sampling of the respective study areas.

In conclusion, present study represents a comprehensive report on prevalence of Eimeria sp. infection in blackbucks of Tal Chhapar Sanctuary, Churu, Rajasthan and the data generated could be of immense help in formulation of effective strategies for prevention and control of coccidiosis in order to upgrade the health and conservation status of black buck population.

\section{Acknowledgement}

The authors would like to sincerely acknowledge the Office of the APCCFs for granting permission to conduct the study in the Tal Chhapar Sanctuary, Churu, Rajasthan. The cooperation of wardens, Ranger and wildlife technicians of Tal Chhapar Sanctuary, Churu are gratefully acknowledged. The authors thankfully acknowledged the financial support and facilities provided by RAJUVAS, Bikaner to carry out the research work.

\section{Conflict of interest}

We declare that we have no conflict of interest.

\section{References}

Akhter, R. and Arshad, M.2006. Arid rangelands in the Cholistan desert (Pakistan). Science et changements planétaires/Secheresse. 17(1-2): 210217.

Cao, Y.F., Yang, Y.B., Duszynski, D.W., Zhu Y.H., Zhang, T.Z., Shang G.Z. and Bian J.H. 2019. Five new species of Eimeria Schneider, 1875 from the endangered Tibetan antelope Pantholops hodgsonii (Abel) (Artiodactyla: Bovidae: Caprinae) in the Hoh Xil Nature Reserve Area of Qinghai Province, China. Syst. Parasitol. 96, 337-346.

Chaudhary, R. B. and Maharjan, M.2017. Parasitic infection in blackbuck (Antilope cervicapra Linnaeus, 1758) of Blackbuck Conservation Area, Bardiya and Shuklaphanta Wildlife Reserve, Kanchanpur, Western Nepal. Nepal Journal of Environmental Science.5: 917.

Coles, G.C., Baur, C., Borgsteede, F.H.M., Geerts, S., Klei, T.R., Taylor, M.A. and Waller, P.J. 1992. Methods for detection of anthelmintics resistance in nematodes of Veterinary importance. Veterinary Parasitolgy.44: 35-44.

Das, S., Dehuri, M., Panda, M.R., Sahoo, N., Mohanty, B.N. and Mahapatra, T. 2018. Gastro-intestinal helminthic infection in herbivore safari at Nandankanan Zoological Park. International Journal of Current Microbiology and Applied Sciences.7(8): 1034-1039.

Debenham, J.J., Cools, F., Midtgaard, F., Robertson, L.J. 2016. Five Species of Coccidia (Apicomplexa: Eimeriidae), Including Four New Species, Identified in the Feces of Blue Wildebeest (Connochaetes taurinus) in Mikumi National Park, Tanzania. J Parasitol. 102(2): 233-8.

Department of Agriculture, Govt. of Rajasthan, www.agriculture.rajasthan. gov.in.

Indian State Forest Report, Forest Survey of 
India. 2015.

IUCN. The IUCN Red List of Threatened Species. Version 2017-2. Available at: www.iucnredlist.org, 2017.

Khanal, P., 2002. Study on the ecology, behaviour and habitat options for the conservation of last remaining Blackbuck population in Nepal by using GIS. A Dissertation Submitted in partial Fulfilment of the Requirements for the Degree in Environmental Sciences, Kathmandu University, Nepal

Kunwar, A., 2015. Habitat Assessment, Conflict Evaluation and Conservation Awareness of Blackbuck, Antelope cervicapra, in Blackbuck Conservation Area, Bardia, Nepal. A report submitted to the Rufford Small Grant for the fulfillment of the $\mathrm{PhD}$ degree.

Liatis, T.K., Monastiridis, A., Panagiotis, B., Sophia, P. and Anastasia, A. 2017.Endoparasites of wild mammals sheltered in wildlife hospitals and rehabilitation centres in Greece.Frontiers in Veterinary Science.4:220.

Lama, S.T., Lama, R.P., Regmi, G.R. and Ghimire, T.R.2015. Prevalence of intestinal parasitic infections in freeranging Red Panda (Ailurus fulgens Cuvier, 1825 (Mammalia: Carnivora: Ailuridae) in Nepal. Journal of Threatened Taxa. 7(8): 7460-7464.

Mir, A.Q., Dua, K., Singla, L.D., Sharma, S. and Singh, M.P.2016. Prevalence of parasitic infection in captive wild animals in Bir Moti Bhag Mini Zoo,
Patiala, Punjab. Veterinary World. 9(6): 540-543.

Pilania, P.K., Manohar, G.S. and Joshi, S.P.2014. Prevalence of gastrointestinal parasites in Black bucks and Chinkara at Bikaner zoo. Veterinary Practitioner.15(2): 276-277.

Singh, P., Gupta, M.P., Singla, L.D., Sharma, S., Sandhu, B.S. and Sharma, D.R. 2006. Parasitic infections in wild herbivores in the Mahendra Choudhury Zoological Park, Chhatbir, Punjab. Zoo's Print Journal.21: 2459- 2461.

Singh, S., Shrivastav, A.B. and Sharma R.K.2009. The epidemiology of gastrointestinal parasitism and body condition in free-ranging herbivores. Journal of Threatened Taxa.1(10): 535- 537.

Soulsby, E.J.L. (1982). Helminths, Arthropods and Protozoa of Domesticated Animals. $7^{\text {th }}$ edition, Bailliere and Tindall, London.

Thronton, J.E., Gavlin, T.J. and Bell, R.R.1973. Parasites of the Black buck antelope (Antelope cervicapra) in Texas. Journal of Wildlife Disease. 9: 160-162.

Thrusfield, M. 2005. Veterinary Epidemiology, second ed. Blackwell Science Ltd., U.K.

Varadharajan, A. and Kandasamy, A. 2000. A survey of gastrointestinal parasites of wild animals in captivity in the V. O. C Park and Mini zoo, Coimbatore. Zoo's PrintJournal.15: 257-258.

\section{How to cite this article:}

Chouhan, A.K., P.K. Pilania, Monika, D.B. Sodha, Bhavana Rathore, D.P. Pateer and Anand Kumar. 2021. Eimeria sp. Infection in Black Bucks (Antilope cervicapra) of Tal Chhapar Sanctuary of Rajasthan. Int.J.Curr.Microbiol.App.Sci. 10(01): 1305-1310. doi: https://doi.org/10.20546/ijcmas.2021.1001.155 